\title{
Electrophysiological correlates of threat processing in spider phobics
}

\author{
IRIS-TATJANA KOLASSA, FRAUKE MUSIAL, ALEXANDER MOHR, RALF H. TRIPPE, AND \\ WOLFGANG H. R. MILTNER \\ Biological and Clinical Psychology, Institute of Psychology, Friedrich Schiller University Jena, Jena, Germany
}

\begin{abstract}
The electrocortical correlates of the processing of feared/fear relevant and neutral stimuli were investigated in a pictorial emotional Stroop paradigm with spider phobic, social phobic, and nonphobic subjects. Subjects identified either the color of red or blue pictures of spiders, birds, or flowers (emotional Stroop task) or the object itself (identification task) by pressing different buttons. No emotional Stroop interference was found for spider phobic subjects when identifying the color of spiders as opposed to neutral stimuli. However, in the object identification task, spider phobic subjects identified spiders significantly faster than birds or flowers. Parietal P300 and P400 amplitudes were enhanced independent of task in spider phobic but not in nonphobic subjects when viewing pictures of spiders, which is consistent with previous studies showing that highly unpleasant and arousing pictures affect parietal late positive potentials.
\end{abstract}

Descriptors: Arousal, Anxiety, Emotional interference, Emotional Stroop, Event related potentials (ERPs), Spider phobia

Fear of spiders is one of the most common phobic disorders. Epidemiological studies of spider phobia found a point preva lence of $5.6 \%$ in women and of $1.2 \%$ in men (Fredrikson, Annas, Fischer, \& Wik, 1996), whereas subclinical fears of spiders are even more prevalent. Although spiders are genuinely feared stimuli for individuals with spider phobia, some authors have suggested that spiders may be so called ancestral "fear relevant stimuli" for all human beings, because their fast detection in earlier humans' environment was presumably of significant sur vival relevance for mankind during evolution. This suggestion was mainly based on the observation that spider stimuli auto matically capture the attention of human subjects and are easily associated with aversive events (Mineka \& Öhman, 2002; Öhman, 1993; Öhman \& Mineka, 2001; Seligman, 1971).

A series of studies has shown that anxious patients, in par ticular individuals with specific phobias, exhibit cognitive biases in the processing of threatening information. Such cognitive bi

Iris Tatjana Kolassa is now at the Department of Psychology, Uni versity of Konstanz, Konstanz, Germany.

This study was funded by a grant (Mi265/6 1) of the German Research Foundation (Deutsche Forschungsgemeinschaft) awarded to W.H.R. Miltner. We would like to thank the German National Academic Foun dation (Studienstiftung des deutschen Volkes) for awarding a doctoral grant to I. T. Kolassa. Thanks are also due to Sandra Riske and Katharina Stoßel for their help in conducting the study. We are also grateful for the helpful comments of the anonymous reviewers of this article.

Address reprint requests to: Dr. Iris Tatjana Kolassa, Department of Psychology, University of Konstanz, 78457 Konstanz, Germany. E mail: Iris.Kolassa@uni konstanz.de. ases in anxiety disorders can be broadly categorized as affecting three stages of information processing: (1) attention and the en coding of stimuli, (2) their elaboration and interpretation, and (3) their storage and retrieval from memory (Cameron, 1997; Mathews \& MacLeod, 1987). The present study focused on the attentional bias in spider phobia: The attention of anxious sub jects is involuntarily drawn to threatening stimuli, and such stimuli are processed with high selectivity and priority. The term "involuntary" emphasizes that attention is captured automati cally by "bottom up" or "stimulus driven" processes without an explicit intention to attend (Egeth \& Yantis, 1997; Eimer, Nattkemper, Schröger, \& Prinz, 1996). Attentional biases have been observed in persons with animal phobia, social phobia, high trait anxiety, generalized anxiety disorder, and posttraumatic stress disorder (Williams, Mark, Watts, MacLeod, \& Mathews, 1997).

Researchers have devised several paradigms to study the at tentional bias in phobia: "detection paradigms" such as visual search paradigms, "facilitation paradigms" such as the dot probe paradigm, and "interference paradigms" such as the emo tional Stroop paradigm.

\section{Emotional Stroop Interference}

The emotional Stroop task is the most commonly used paradigm for measuring attentional biases in phobia. In this modified ver sion of the original Stroop task (Stroop, 1935), the time it takes subjects to identify the color of words or pictures varying in personal emotional significance is measured. The difference in color naming latencies between emotional and neutral stimuli provides a measure of the attentional bias. The phenomenon that 
threatening stimulus attributes impair the processing of non threatening stimulus characteristics has been called emotional in terference. For instance, anxiety patients show selectively longer color naming latencies for anxiety relevant words than for neu tral words (e.g., Becker, Rinck, Margraf, \& Roth, 2001; Hope, Rapee, Heimberg, \& Dombeck, 1990; Mathews \& MacLeod, 1985; for an overview see Williams et al., 1997).

A number of studies found emotional interference in animal phobic subjects when color naming fear related stimuli (Kindt \& Brosschot, 1997; Lavy \& van den Hout, 1993; Lavy, van den Hout, \& Arntz, 1993; Martin, Horder, \& Gregory, 1992; Martin \& Jones, 1995; Watts, McKenna, Sharrock, \& Trezise, 1986). However, results are far from consistent: Whereas some studies found no clear interference for spider pictures (Constantine, McNally, \& Hornig, 2001), others found less interference (Lavy \& van den Hout, 1993) or similar interference (Kindt \& Brosschot, 1997) for spider pictures as compared to spider related words. It seems that various influencing factors have to be considered when trying to integrate the results of different emotional Stroop par adigms. These are the types of stimuli used (pictures vs. words; Kindt \& Brosschot, 1997, 1999), the response mode (vocal vs. manual; MacLeod, 1991; Redding \& Gerjets, 1977), the exper imental design (blocked vs. randomized; Holle, Neely, \& Heimb erg, 1997; Kindt, Bierman, \& Brosschot, 1997; McNally, Amir, \& Lipke, 1996; Richards, French, Johnson, Naparstek, \& Williams, 1992; Waters \& Feyerabend, 2000), and the age of participants (children vs. adults; Kindt \& Brosschot, 1999; Kindt \& van den Hout, 2001; Kindt, van den Hout, de Jong, \& Hoekzema, 2000).

\section{Event-Related Potentials in the Processing of Emotional Stimuli}

Whereas many studies investigated the attentional bias in phobic subjects by measuring reaction times (RTs) or response errors, in the current study we investigate the cortical correlates of emotional Stroop interference by recording event related potentials (ERPs). Several studies have shown larger parietal late positive potentials (LPPs) in response to emotional stimuli, both pleasant and un pleasant, as compared to neutral stimuli (Cuthbert, Schupp, Bradley, Birbaumer, \& Lang, 2000; Diedrich, Naumann, Maier, Becker, \& Bartussek, 1997; Johnston, Miller, \& Burleson, 1986; Keil et al., 2001, 2002; Laurian, Bader, Lanares, \& Oros, 1991; Mini, Palomba, Angrilli, \& Bravi, 1996; Palomba, Angrilli, \& Mini, 1997; Radilovà, 1982; Radilovà, Figar, \& Radil, 1983, 1984; Schupp et al., 2000). In a previous study that investigated ERPs in spider phobics when viewing feared compared to neutral stimuli, Gutberlet and Miltner (1999) found that the presentation of feared and fear relevant stimuli led to enhanced P300 ampli tudes for the feared object in the corresponding specific phobia group, that is, spider phobics showed enhanced P300 amplitudes for spiders but not for snakes, and snake phobics showed en hanced P300 amplitudes for snakes but not for spiders.

This variation of parietal LPPs with the emotionality of visual stimuli has been interpreted as indicative of deeper processing of emotional information and a more intense commitment of attent ional resources to emotional stimuli (Lang, Bradley, \& Cuthbert, 1997; Palomba et al., 1997). Recently, the influence of the two dimensions of emotional valence and arousal of stimuli on ERPs has been studied more closely. Ito, Larsen, Smith, and Cacioppo (1998) found larger LPPs in response to negative than to positive stimuli with equal arousal classifications, indicating a larger in fluence of the emotional valence than the arousal dimension. On the other hand, Schupp et al. (2000) as well as Cuthbert et al. (2000) found high arousing pleasant and unpleasant pictures to elicit larger amplitudes of LPP components than low arousing stimuli of the same valence. However, a basic difficulty of these results lies in the problem that valence and arousal of stimuli are strongly associated, that is, highly positive and highly negative stimuli are in general also evaluated as more arousing (Lang et al., 1997). Thus, the individual impact of valence and arousal on these ERP components is still unclear; however, although both dimen sions appear to have an effect, a larger influence of arousal is slowly gaining acceptance in the literature.

\section{Aims and Hypotheses}

This study investigated the electrocortical correlates of the at tentional bias in individuals with spider phobia by means of a pictorial emotional Stroop paradigm on the one hand and an identification task on the other hand. Subjects were presented red or blue colored pictures of spiders, birds, or flowers and identified either the color of the stimuli (emotional Stroop task) or the objects themselves (identification task). Whereas previous emotional Stroop studies mostly relied on verbal stimuli, this study used pictorial stimuli because of their higher ecological validity. In addition, manual instead of verbal responses were recorded to avoid artifacts in the recording of ERPs due to speech related movements.

In addition to replicating previous RT studies investigating emotional Stroop interference in spider phobics, the main aim of this study was to identify the electrocortical correlates of the neuronal processes underlying this interference. The focus of re search was placed on the amplitude of the P300 and related ERP components because of the well documented influence of highly emotional stimuli on components in this latency range.

In the Stroop task, we anticipated a specific emotional inter ference in spider phobics but not in controls and social phobics, expressed as longer RTs for the color identification of spider images as compared to neutral pictures. In the object identifica tion task, we hypothesized finding a general facilitation effect for fear relevant stimuli in phobic and nonphobic subjects, that is, a faster identification of spiders than of birds and flowers. Because, according to Öhman (Öhman, 1979; Öhman, Esteves, Flykt, \& Soares, 1993), fear relevant stimuli are processed with high se lectivity and priority due to their ancestral valence, and because this should apply not only to spider phobics but to all subjects, faster RTs for the identification of spiders should be found in general. However, this facilitation effect should be particularly pronounced in spider phobics, who show an attentional bias for their feared object. Therefore, an additional specific facilitation effect in spider phobics when identifying spiders as compared to birds or flowers was expected.

Regarding ERPs we hypothesized that because spiders are generally evaluated as more negative and arousing than birds or flowers, larger parietal LPPs (P300 and related components) should be observed for spider pictures in all subjects (general valence/arousal effect). In addition, because spiders are particu larly unpleasant and arousing for spider phobics, these subjects should show even larger amplitudes in the P300 latency range for spiders (specific valence/arousal effect).

\section{Methods}

\section{Pilot Study}

In a pilot study, 14 participants with spider phobia (5 male, 9 female), 11 participants with social phobia (6 male, 5 female), 
Table 1. Mean Valence and Arousal Ratings (M) and Standard Deviations (SD) for Pictures of Spiders, Birds, and Flowers for Each Group

\begin{tabular}{|c|c|c|c|c|c|c|}
\hline & \multicolumn{2}{|c|}{ Controls } & \multicolumn{2}{|c|}{ Spider phobics } & \multicolumn{2}{|c|}{ Social phobics } \\
\hline & $M$ & $S D$ & $M$ & $S D$ & $M$ & $S D$ \\
\hline \multicolumn{7}{|l|}{ Valence } \\
\hline Spider & 3.74 & 1.59 & 1.17 & 0.89 & 3.18 & 0.69 \\
\hline Bird & 6.04 & 0.80 & 5.37 & 1.16 & 5.42 & 0.82 \\
\hline Flower & 6.24 & 1.03 & 5.86 & 1.05 & 5.65 & 0.94 \\
\hline \multicolumn{7}{|l|}{ Arousal } \\
\hline Spider & 2.93 & 1.52 & 5.90 & 1.20 & 3.06 & 1.21 \\
\hline Bird & 1.61 & 1.22 & 2.01 & 1.26 & 1.68 & 1.10 \\
\hline Flower & 1.47 & 1.19 & 1.75 & 1.13 & 1.50 & 1.03 \\
\hline
\end{tabular}

Note: The original scale from Lang (1980) was slightly modified: The SAM scale ranged from 0 to 8 with 0 highly unpleasant/low arousing and 8 highly pleasant/highly arousing.

and 14 controls ( 7 male, 7 female) rated the stimuli used in this study (pictures of spiders, birds, and flowers) as to their affective valence and arousal with an adapted version of the Self Assess ment Manikin Scale (SAM; Lang, 1980). The SAM is a relatively culture free pictographic assessment instrument that has been used in various emotion studies. Participants' mean age was 23.4 years $(S D=3.8$; age range 1733 years). ANOVAs with be tween factor Group and repeated measures factor Object were calculated.

Table 1 depicts affective valence and arousal ratings of the different groups for images of spiders, birds, and flowers. A main effect of object showed that all participants rated spider images as significantly more unpleasant, $F(2,72)=168.11, p=.0005$, $\varepsilon=.77, \eta^{2}=.82$, and arousing, $F(2,72)=137.64, p=.0005$, $\varepsilon=.57, \eta^{2}=.79$, than pictures of birds or flowers. However, the significant interaction of Group $\times$ Object revealed that spider phobics rated pictures of spiders as significantly more unpleas ant, $F(4,72)=8.92, p=.0005, \varepsilon=.75, \eta^{2}=.33$, and arousing, $F(4,72)=20.48, p=.0005, \varepsilon=.57, \eta^{2}=.53$, than controls or social phobics. Thus, the pictures used in the study were suitable to elicit the specific reactions in each group.

\section{Participants}

Fifty seven participants (mean age 23.2 years, $S D=3.4$, age range 1932 years) participated in the study: 19 spider phobics ( 9 male, 10 female), 19 normal controls ( 10 male, 9 female), and 19 social phobics ( 10 male, 9 female). Individuals with social phobia represented a clinical control group in addition to the control group composed of nonphobic participants. Fifty four partici pants were right handed and 3 left handed, as measured by the Edinburgh handedness questionnaire (Oldfield, 1971). All par ticipants had normal or corrected to normal vision.
Participants were recruited by newspaper advertisement and public announcement within the university student population. In a preliminary interview, participants were screened with the Structured Clinical Interview for DSM IV (SCID I; Wittchen, Wunderlich, Gruschwitz, \& Zaudig, 1997). To be accepted for the study, participants had to be free of any current or previous disorder according to DSM IV except for a diagnosis of Spider Phobia for the spider phobic group and a diagnosis of Social Phobia for the social phobic group. Furthermore, participants were not accepted if they received any psychotropic medication. Before participation, participants completed the German ver sions of the Spider Questionnaire (SPQ; Klorman, Weerts, Hast ings, Melamed, \& Lang, 1974), the Social Phobia and Anxiety Inventory (SPAI; Fydrich, 2002; Turner, Beidel, Dancu, \& Stanley, 1989), the Beck Depression Inventory (BDI; Ha utzinger, Bailer, Worall, \& Keller, 1995), and the Trait scale of the State Trait Anxiety Inventory (STAI T; Laux, Glanzmann, Schaffner, \& Spielberger, 1981). Mean questionnaire scores (and $S D$ ) for each group are depicted in Table 2.

It is well known that social phobia is highly comorbid with depression (Merikangas et al., 1996; Schneier, Johnson, Hornig, Liebowitz, \& Weissman, 1992; Stein et al., 2001). Although so cial phobics with a clinically significant depression were not in cluded in the study, the participating social phobics scored on average higher on the BDI than the control and spider phobic participants, with elevated but not clinically significant BDI scores, $M=9.42, S D=7.09$.

The procedures were approved by the ethics committee of the University of Jena. Participants provided informed consent and were paid $6 €$ per hour for participation. In addition, spider phobics could participate in a spider phobia therapy (Öst, 1989), and social phobics were offered participation in a 10 session group training of social competences (Hinsch \& Pfingsten, 2002).

\section{Paradigm}

The experiment consisted of two blocks, each with 90 pictures of spiders, flowers, and birds (30 of each). Forty five pictures were colored red, the others blue. In one block, participants were in structed to identify the color of the object (blue, red), whereas in the other block, participants were requested to identify the object itself (spider, flower, bird) by pressing the appropriate button (buttons 7, 8, or 9 on an alphanumeric button box) with the index finger of their dominant hand as fast and as accurately as pos sible. During initial training for each task, six stimuli of each category were shown. Participants could repeat the practice task as long as they considered repetition necessary, so that they could react without looking at the button box. Stimuli were shown for $1 \mathrm{~s}$ with a variable interstimulus interval of $23 \mathrm{~s}$.

In both blocks, participants were presented trial unique stim uli. The order of the stimuli was pseudorandomized with the

Table 2. Mean Questionnaire Values ( $M$ ) and Standard Deviations (SD) for Each Group

\begin{tabular}{|c|c|c|c|c|c|}
\hline & Control group & Spider phobics & Social phobics & \multicolumn{2}{|c|}{ Main effects and comparisons } \\
\hline Spider Questionnaire & $2.47(1.78)$ & $20.89(2.87)$ & $2.58(1.95)$ & $F(2,54)$ & $422.44, p<.001^{\mathrm{a}, \mathrm{b}}$ \\
\hline Social Phobia and Anxiety Inventory & $33.53(16.89)$ & $43.90(15.25)$ & $126.81(18.17)$ & $F(2,54)$ & $175.68, p<.001^{\mathrm{b}, \mathrm{c}}$ \\
\hline Beck Depression Inventory & $2.68(2.71)$ & $4.79(4.67)$ & $9.42(7.09)$ & $F(2,54)$ & $8.52, p \quad .001^{\mathrm{b}, \mathrm{c}}$ \\
\hline Trait State Anxiety Inventory (Trait Version) & $30.79(5.92)$ & $33.32(7.86)$ & $50.47(6.61)$ & $F(2,54)$ & $46.52, p<.001^{\mathrm{b}, \mathrm{c}}$ \\
\hline
\end{tabular}

Note: The German scores of the Social Phobia and Anxiety Inventory were transformed into the original scores (Turner et al., 1989).

${ }^{a}$ Control group is different than spider phobics $(p<.05)$.

${ }^{\mathrm{b}}$ Spider phobics are different than social phobics $(p<.05)$.

${ }^{\mathrm{c}}$ Control group is different than social phobics $(p<.05)$. 
following conditions: the same color was only allowed four times in a row and the same type of object only two times in a row, in order to avoid expectations of which color or object would be presented next. The order of the two conditions and the map pings of classifications to keys were randomized across partic ipants.

\section{Assessment and Analysis of EEG}

During the recording session participants sat in a comfortable chair in a sound attenuated room. Stimuli were shown on a 20 in. Sony monitor (resolution $800 \times 600$ ) placed $1.1 \mathrm{~m}$ in front of the participant. EEG was recorded with a 62 electrode montage (easy cap, Falk Minow Systems, Munich, Germany) according to the international 1010 system (Chatrian, Lettich, \& Nelson, 1998) with $\mathrm{Cz}$ as a reference electrode. Electrode impedances were kept below $5 \mathrm{k} \Omega$. In addition, vertical and horizontal elect rooculograms (VEOG and HEOG) were recorded for off line correction of eye movements and blink artifacts. All signals were sampled continuously in AC mode at a rate of $500 \mathrm{~Hz}$.

The EEG data were filtered off line (low pass $=30 \mathrm{~Hz}, 24 \mathrm{~dB} /$ oct; high pass $=0.1 \mathrm{~Hz}, 24 \mathrm{~dB} /$ oct), segmented for the time pe riod of $200 \mathrm{~ms}$ before and $900 \mathrm{~ms}$ after stimulus onset, corrected for blinks (Gratton, Coles, \& Donchin, 1983), and screened for artifacts using the software Brain Vision Analyzer 1.04 (Brain Products GmbH, Munich, Germany). Trials with artifacts (am plitude deviations of $\pm 150 \mu \mathrm{V}$ ) were excluded from analysis. Mean averages for each condition and participant were baseline corrected by subtracting the average activity of the last $200 \mathrm{~ms}$ before stimulus presentation from all succeeding data points. Then the data were rereferenced to linked earlobes. One partic ipant (male social phobic) was excluded from further analysis because of extreme alpha activity.

Multiple late positive components with maximal amplitudes over electrode $\mathrm{Pz}$ were observed in the latency range of 200600 ms. A temporal Principal Components Analysis (PCA) was cal culated over the averages for each condition and for each of 21 electrodes (F3, Fz, F4, FC3, FCz, FC4, C3, Cz, C4, CP3, CPz, $\mathrm{CP} 4, \mathrm{P} 3, \mathrm{Pz}, \mathrm{P} 4, \mathrm{PO} 3, \mathrm{POz}, \mathrm{PO} 4, \mathrm{O} 1, \mathrm{Oz}, \mathrm{O} 2$ ) for each partic ipant. Time condense factor was 5 , that is, every fifth data point was included in the analysis to reduce the amount of data and thus processing time. The PCA was calculated by analyzing the covariances among time points for all conditions and partici pants, followed by varimax rotation. Six factors, accounting for over $90 \%$ of the variance, were retained and are depicted in Figure 1. Factor 1 accounted for $61.5 \%$ of total variance, factor 2 for $14.5 \%$, factor 3 for $5.7 \%$, factor 4 for $3.6 \%$, factor 5 for $3.3 \%$, and factor 6 for $1.8 \%$ (see Figure 1). Of importance are factors 2 and 5 , which can be interpreted as a positive component $200400 \mathrm{~ms}$ poststimulus (P300) and a second positive compo nent $400600 \mathrm{~ms}$ poststimulus (P400). This interpretation was supported by the following findings: When ERPs loading highly on factors 2 and 5 were averaged, they were positive in voltage. In addition, the posterior spatial distributions of these two compo nents, as depicted in Figure 1, fit the interpretation as P300 and P400 components. These results are consistent with previous studies that found multiple late positive components in response to emotional stimuli (e.g., Johnston et al., 1986; Mini et al., 1996). The P300 and P400 amplitudes were the focus of the statistical analysis.

Peaks of P300 (200 $400 \mathrm{~ms}$ ) and P400 components (400 600 $\mathrm{ms}$ ) were detected at electrode $\mathrm{Pz}$ and exported for electrodes F3, $\mathrm{Fz}, \mathrm{F} 4, \mathrm{C} 3, \mathrm{Cz}, \mathrm{C} 4, \mathrm{P} 3, \mathrm{Pz}, \mathrm{P} 4, \mathrm{O} 1, \mathrm{Oz}$, and O2. Figure 2 depicts the topographical distribution of the P300 amplitudes across groups and stimuli. Topographical distributions of the P400 component were very similar and are not depicted.

\section{Statistical Analysis}

For the analysis of RTs, all trials were excluded in which no reaction occurred, the answer was wrong, or RT was below 200 $\mathrm{ms}$. To examine the influence of task and picture type on RT, a $3 \times 2 \times 3$ ANOVA with between factor Group and repeated measures factors Task (identify color, identify object) and object (spider, flower, bird) was performed. ERP data was analyzed by means of a $3 \times 2 \times 3 \times 3 \times 4$ ANOVA with between factor Group and repeated measures factors Task, Object, Laterality (left, central, right), and Site (frontal, central, parietal, occipital). To correct for violations of sphericity, Greenhouse Geisser $\varepsilon$ corrections were used (Greenhouse \& Geisser, 1958). Whenever significant effects were revealed in the ANOVA, subsequent ANOVAs and least significant difference (LSD) tests were ap plied to identify the sources of main effects and interactions. Planned contrasts were calculated to test hypotheses. Eta squared, $\eta^{2}$, a measure of effect size, is reported.

\section{Results}

\section{Behavioral Data and Reaction Times}

The analysis of accuracy data showed no significant difference between groups in total mistakes (missings and errors), Kruskal Wallis $\chi^{2}(2, N=57)=.52, p=.77$. Overall, subjects failed to respond in $2.26 \%$ of all trials, and incorrect responses were observed in $1.66 \%$ of all trials.

Table 3 depicts mean RTs and standard deviations for the color and object identification of spiders, birds, and flowers for each group. In general, RTs were significantly faster when sub jects identified the color of a stimulus than when the object itself had to be classified, main effect of Task, $F(1,54)=103.97$, $p=.0005, \eta^{2}=.66$. There was no evidence for an emotional Stroop interference effect, that is, spider phobics did not show prolonged response latencies when identifying the color of spi ders as compared to birds or flowers, or as compared to social phobics and controls. However, there was a significant interac tion of Group $\times$ Task $\times$ Object, $F(2,108)=2.95, p=.02$, $\varepsilon=.99, \eta^{2}=.1$. Planned contrasts showed that spider phobics identified spiders significantly faster than birds, $p=.001$, or flow ers, $p=.002$, and identified spiders significantly faster than the control, $p=.001$, and social phobic groups, $p=.0005$. There were no differences between RTs for different stimuli in the other groups.

Table 3. Mean Reaction Times ( $M$ ) and Standard Deviations (SD) for the Color and Object Identification of Pictures of Spiders, Birds, and Flowers for Each Group

\begin{tabular}{|c|c|c|c|c|c|c|}
\hline & \multicolumn{2}{|c|}{ Controls } & \multicolumn{2}{|c|}{ Spider phobics } & \multicolumn{2}{|c|}{ Social phobics } \\
\hline & $M$ & $S D$ & $M$ & $S D$ & $M$ & $S D$ \\
\hline \multicolumn{7}{|c|}{ Color identification } \\
\hline Spider & 541.74 & 112.52 & 517.23 & 66.88 & 526.88 & 85.77 \\
\hline Bird & 519.79 & 92.93 & 510.08 & 102.29 & 523.36 & 89.78 \\
\hline Flower & 540.44 & 105.31 & 523.64 & 94.82 & 529.28 & 86.83 \\
\hline \multicolumn{7}{|c|}{ Object identification } \\
\hline Spider & 606.66 & 80.89 & 521.04 & 70.64 & 633.13 & 84.42 \\
\hline Bird & 615.70 & 58.00 & 589.54 & 79.77 & 632.83 & 71.86 \\
\hline Flower & 620.94 & 76.96 & 599.30 & 90.33 & 638.66 & 81.32 \\
\hline
\end{tabular}



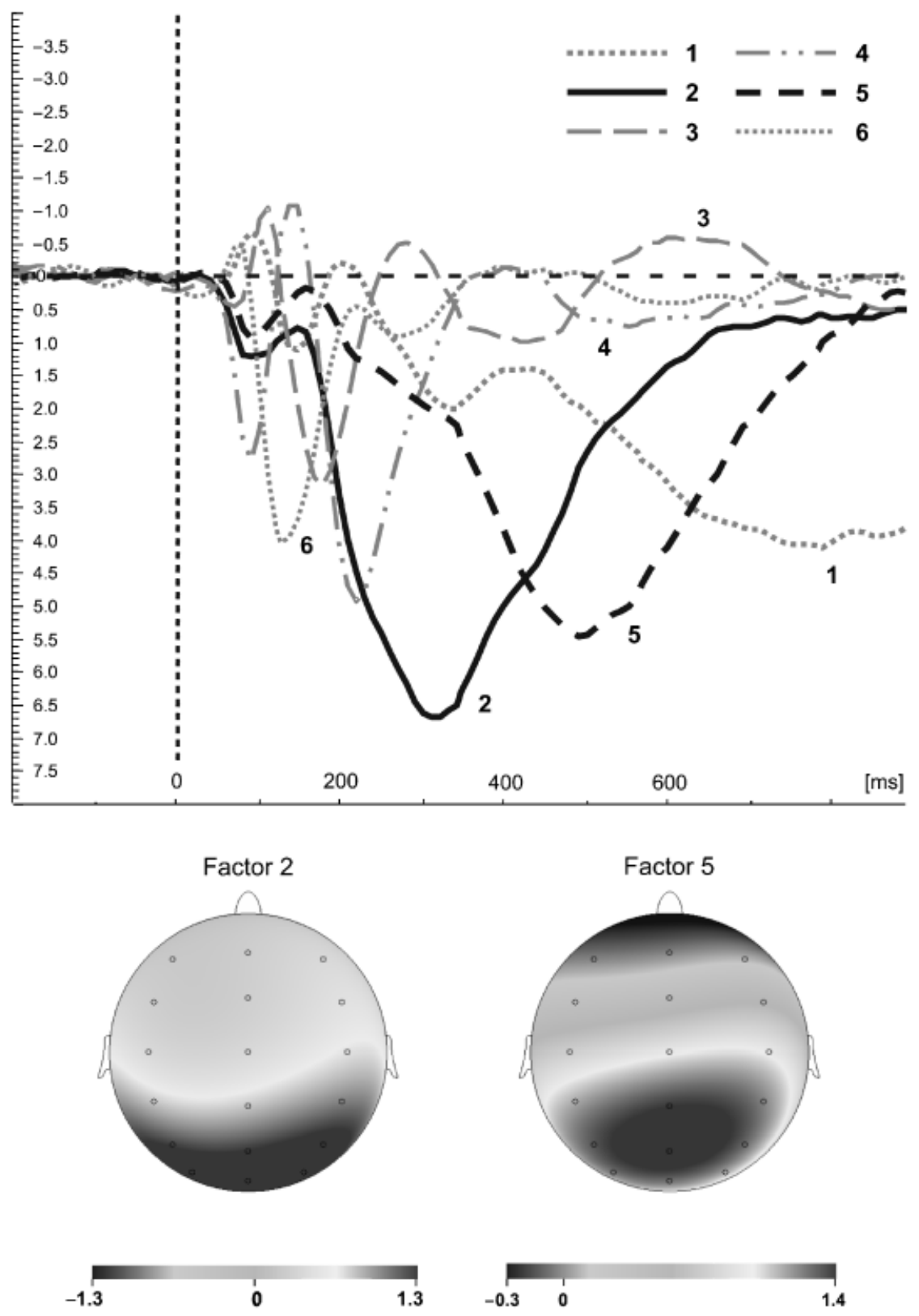

Figure 1. Top: Results of Principal Component Analysis (PCA). Factor 1 accounted for $61.5 \%$ of total variance, factor 2 for $14.5 \%$, factor 3 for $5.7 \%$, factor 4 for $3.6 \%$, factor 5 for $3.3 \%$, and factor 6 for $1.8 \%$. Bottom: Mean component values over subjects for factor 2 (left) and factor 5 (right). Factor 2 shows an occipito parietal distribution, factor 5 a more parietal distribution.

\section{Event-Related Potentials}

Figure 3 shows grand average ERPs at Pz in response to pictures of spiders, birds, and flowers for each group and for both tasks.

Analysis of P300 amplitude. ANOVA revealed a main effect of Site, $F(3,159)=106.85, p=.0005, \varepsilon=.46, \eta^{2}=.67$. P300 am plitudes were maximal over parietal sites. In view of the fact that effects would be very hard to interpret in a five factor ANOVA and that parietal electrodes are classically used for the detection and analysis of LPPs, we decided to exclude the factor Site from all further analyses and conduct further analyses based only on parietal electrode sites.

As can be seen in Table 4, all subjects showed larger P300 amplitudes in response to pictures of spiders compared to pictures of birds or flowers, main effect of Object, $F(2,106)=32.77$, $p=.0005, \varepsilon=.97, \eta^{2}=.38$. However, spider phobics showed par ticularly large P300 amplitudes when exposed to spider pictures, interaction Group $\times$ Object, $F(4,106)=8.84, p=.0005, \varepsilon=.97$, $\eta^{2}=.25$. Subsequent ANOVAs calculated separately for each group revealed that the main effect of Object was mainly due to spider phobics, main effect of Object, $F(2,36)=37.71, p=.0005$, $\varepsilon=.85, \eta^{2}=.68$, whereas controls showed a significant main effect of Object of smaller magnitude, $F(2,36)=6.83, p=.003, \varepsilon=1$, $\eta^{2}=.28$, and social phobics did not show such an effect, $F(2,34)=1.93, p=.17, \varepsilon=.86, \eta^{2}=.1$. Simple contrasts revealed that spider phobics showed significantly larger P300 amplitudes when exposed to pictures of spiders as compared to birds, $p=.0005$, and flowers, $p=.0005$. For controls only the contrast spider versus flower was significant, $p=.002$. However, an ANOVA calculated separately for spider stimuli did not show 
P300 Spider Phobics
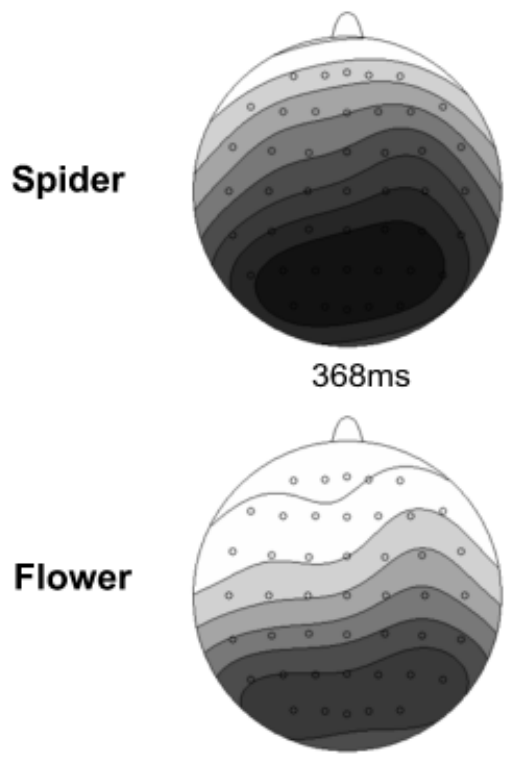

340ms

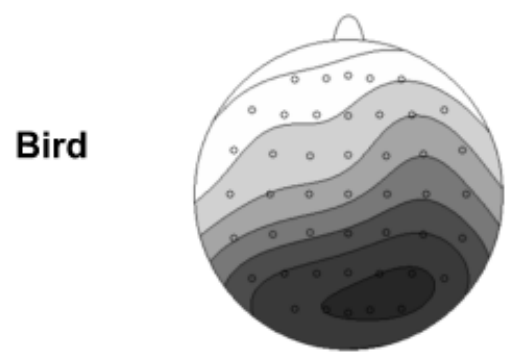

$344 \mathrm{~ms}$
Controls
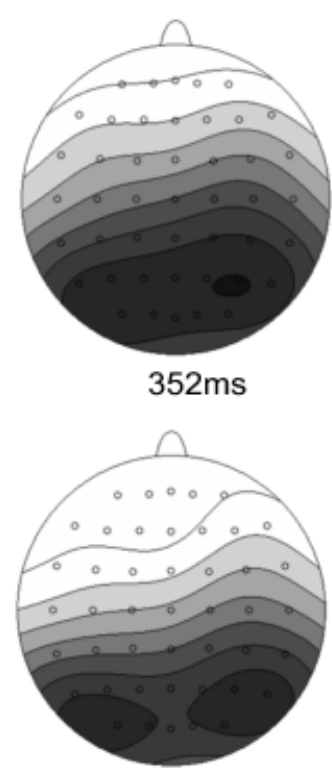

$340 \mathrm{~ms}$

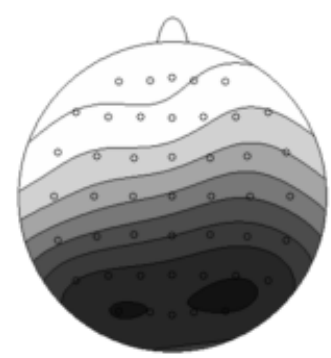

$346 \mathrm{~ms}$

\section{Social Phobics}
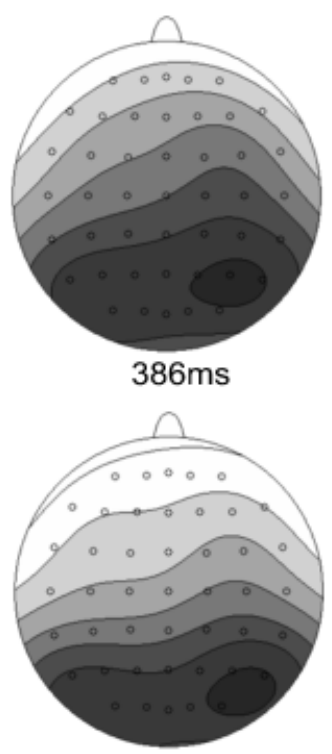

$348 \mathrm{~ms}$

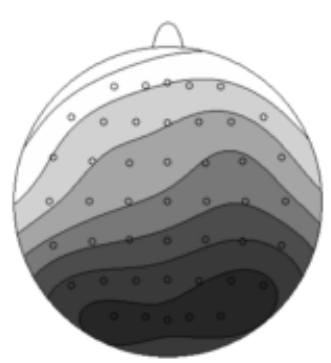

$374 \mathrm{~ms}$

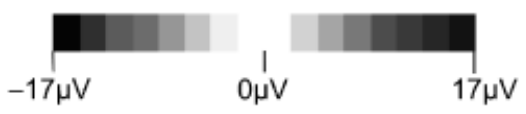

Figure 2. Topographical maps of the $\mathrm{P} 300$ component for each object and each group. A large, broadly distributed parietal positive deflection is visible in all subjects for each object, which is particularly pronounced in spider phobic subjects viewing pictures of spiders. Topographical maps of the P400 component were very similar.

a significant effect of Group, $F(2,53)=2.44, p=.1, \eta^{2}=.84$. Thus, although there seem to be clear differences between spider phobics and both control groups in mean P300 amplitudes in response to spider pictures, these differences represent merely a trend.

Table 4. Mean P300 Amplitudes (M) and Standard Deviations (SD) for the Color and Object Identification of Pictures of Spiders, Birds, and Flowers for Each Group

\begin{tabular}{|c|c|c|c|c|c|c|}
\hline & \multicolumn{2}{|c|}{ Controls } & \multicolumn{2}{|c|}{ Spider phobics } & \multicolumn{2}{|c|}{ Social phobics } \\
\hline & $M$ & $S D$ & $M$ & $S D$ & $M$ & $S D$ \\
\hline \multicolumn{7}{|c|}{ Color identification } \\
\hline Spider & 10.39 & 5.73 & 12.43 & 4.55 & 10.32 & 5.10 \\
\hline Bird & 10.30 & 5.35 & 9.51 & 5.28 & 9.91 & 4.38 \\
\hline Flower & 9.31 & 5.71 & 8.28 & 3.88 & 9.02 & 4.00 \\
\hline \multicolumn{7}{|c|}{ Object identification } \\
\hline Spider & 9.30 & 4.83 & 13.01 & 6.14 & 9.74 & 4.53 \\
\hline Bird & 8.35 & 4.08 & 7.73 & 4.81 & 8.94 & 3.22 \\
\hline Flower & 6.60 & 3.74 & 6.88 & 3.76 & 8.04 & 3.42 \\
\hline
\end{tabular}

Furthermore, a main effect of Laterality, $F(2,106)=19.54$, $p=.0005, \varepsilon=.82, \quad \eta^{2}=.27$, and subsequent comparisons revealed that $\mathrm{P} 300$ amplitudes were generally larger over right than left, $p=.0005$, and central electrode sites, $p=.01$. In addition, the significant interaction Object $\times$ Laterality, $F(4,212)=15.27, p=.0005, \varepsilon=.79, \eta^{2}=.22$, was analyzed by subsequent ANOVAs calculated separately for each object. LSD pairwise comparisons indicated that pictures of birds and flowers led to significantly larger P300 amplitudes over right versus left (birds, $p=.0005$; flowers, $p=.0005$ ) and over right versus cen tral sites (birds, $p=.02$; flowers, $p=.0005$ ). P300 amplitudes in response to spider pictures were also significantly larger over the right as compared to the left hemisphere, $p=.001$; however, there was no significant difference in P300 amplitude between central and right sites.

Analysis of P400 amplitude. The analysis of P400 amplitudes yielded similar results. As depicted in Table 5, spider phobics clearly showed enhanced $\mathrm{P} 400$ amplitudes in response to spider 

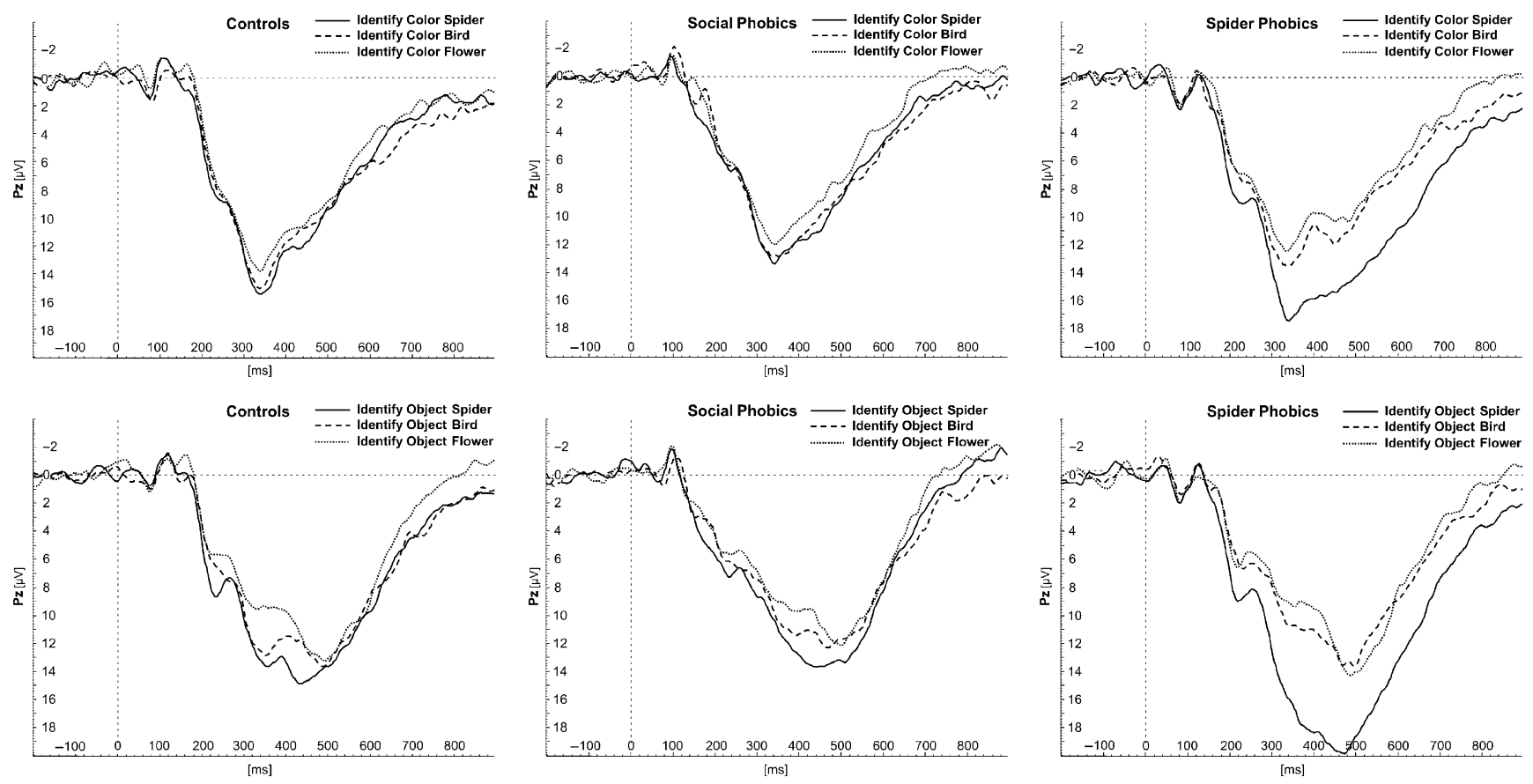

Figure 3. Event related potentials on electrode Pz. Depicted are ERPs to Spiders, Birds, and Flowers for both tasks and for each group.

pictures independently of task, whereas this effect was less pro nounced in social phobics and controls, interaction Group $\times$ Object, $F(4,106)=5.31, p=.001, \varepsilon=.9, \eta^{2}=.17$. Subsequent separate ANOVAs for each group revealed that a main effect of Object was only present in spider phobics, $F(2,36)=15.19$, $p=.0005, \varepsilon=.79, \eta^{2}=.46$, was not present in controls and failed significance in social phobics, $F(2,34)=3.1, p=.06, \varepsilon=.98$, $\eta^{2}=.15$. Separate analyses for both tasks revealed that social phobics showed significantly larger amplitudes for spiders than birds, $p=.02$, and flowers, $p=.05$, in the object but not in the color identification task. In spider phobics, simple contrasts re vealed significantly larger $\mathrm{P} 400$ amplitudes in response to spider pictures than in response to flower, $p=.001$, or bird pictures, $p=.0005$. In contrast to the $\mathrm{P} 300$ results, an ANOVA calculated separately for the spider pictures showed a significant effect of Group, $F(2,53)=3.12, p=.05, \eta^{2}=.1$. Simple contrasts revealed that spider phobics exhibited significantly larger $\mathrm{P} 400$ amplitudes in response to spider pictures than controls, $p=.05$, and social phobics, $p=.03$.

Table 5. Mean P400 Amplitudes (M) and Standard Deviations (SD) for the Color and Object Identification of Pictures of Spiders, Birds, and Flowers for Each Group

\begin{tabular}{|c|c|c|c|c|c|c|}
\hline & \multicolumn{2}{|c|}{ Controls } & \multicolumn{2}{|c|}{ Spider phobics } & \multicolumn{2}{|c|}{ Social phobics } \\
\hline & $M$ & $S D$ & $M$ & $S D$ & $M$ & $S D$ \\
\hline \multicolumn{7}{|c|}{ Color identification } \\
\hline Spider & 12.54 & 5.41 & 15.93 & 5.91 & 11.55 & 4.73 \\
\hline Bird & 11.73 & 4.57 & 12.37 & 6.44 & 11.56 & 4.89 \\
\hline Flower & 11.98 & 4.91 & 11.67 & 5.65 & 10.52 & 3.76 \\
\hline \multicolumn{7}{|c|}{ Object identification } \\
\hline Spider & 15.49 & 6.65 & 19.41 & 7.55 & 15.39 & 4.92 \\
\hline Bird & 14.68 & 4.56 & 13.69 & 7.51 & 13.57 & 4.46 \\
\hline Flower & 14.33 & 3.62 & 14.87 & 6.90 & 13.66 & 5.35 \\
\hline
\end{tabular}

In addition, a main effect of Laterality, $F(2,106)=20.66$, $p=.0005, \varepsilon=.95, \eta^{2}=.28$, and subsequent LSD pairwise com parisons revealed that $\mathrm{P} 400$ amplitudes were significantly larger over right than left, $p=.0005$, and over central than left sites, $p=.0005$. However, there was a significant interaction Object $\times$ Laterality, $F(4,212)=18.98, p=.0005, \varepsilon=.83, \eta^{2}=.26$. LSD pairwise comparisons showed that for all objects P400 ampli tudes were larger over right than left sites (birds, $p=.0005$; flowers, $p=.001$; spiders, $p=.007)$. However, whereas pictures of birds and flowers induced similar amplitudes over central and right sites, pictures of spiders led to larger P400 amplitudes over central than right sites, $p=.001$.

\section{Discussion}

This study found evidence for enhanced parietal late positive potentials in spider phobics when they viewed pictures of their feared object compared to neutral objects, and this effect was independent of the performed task. Thus, the hypothesis of a specific valence/arousal effect on parietal LPPs in spider phobic subjects was confirmed. However, the hypothesis of a general valence/arousal effect of spider pictures on P300 and P400 am plitude was only partially confirmed. Controls, but not social phobics, showed significantly larger P300 amplitudes for spiders as compared to flowers, although social phobics exerted a ten dency toward larger P400 amplitudes when processing images of spiders as compared to flowers.

The reaction time data showed a specific facilitation effect in spider phobics for their feared object: Spider phobics identified spiders significantly faster than social phobics and controls. However, spider phobics also identified neutral objects signifi cantly faster than social phobics, and they also tended to be faster than controls in this task. There was also no evidence of a general facilitation for fear relevant stimuli: Neither social phobics nor controls responded significantly faster to spider pictures than to 
pictures of birds or flowers. In contrast to the hypotheses, no emotional interference was obtained for individuals with spider phobia requested to identify the color of spiders.

\section{Late Positive Potentials (LPPs)}

The ERP results corroborate previous studies that found evi dence for larger LPPs for emotional as compared to neutral stimuli (e.g., Cuthbert et al., 2000; Ito et al., 1998; Johnston et al., 1986, Mini et al., 1996; Palomba et al., 1997; Schupp et al., 2000) and larger P300 amplitudes in animal phobics in response to pictures of their feared object (Gutberlet \& Miltner, 1999). In an fMRI study on the processing of pleasant, neutral, and unpleas ant pictures, Lang et al. (1998) found clusters of more extensive bilateral activation in the occipital cortex and in the right inferior and superior parietal lobules for emotional (pleasant and un pleasant) stimuli. Thus, highly arousing pictures generated more extensive activation than neutral pictures in occipital sensory cortex, a result that is consistent with the present observation of enhanced occipito parietal P300 and parietal P400 amplitudes for feared spider stimuli in the spider phobic group. Highly un pleasant and arousing stimuli, such as a spider for a spider phobic individual, seem to induce more extensive activity in primary and higher perceptual processing areas of the brain. Whereas Schupp, Junghöfer, Weike, and Hamm (2003) reported evidence for an increased early posterior negativity (EPN) for pleasant and un pleasant pictures, the present study primarily found evidence for an augmented late parietal positive potential in spider phobics for pictures of the feared object. Lang et al. (1998) suggested that this increased activity in perceptual processing areas for emotional as compared to neutral stimuli implies reentrant processing from more anterior brain sites such as the anterior cingulate or the amygdala. The observation of multiple late positive components (P300 and P400) is consistent with such a reentrant processing from sites more anterior in the brain.

One important finding of the present study is that, independ ently of the performed task, spider phobics showed larger LPPs when processing pictures of spiders. This is consistent with stud ies by Diedrich et al. (1997) and Naumann, Becker, Maier, Diedrich, and Bartussek (1997), who reported larger P300 am plitudes for emotional (positive or negative) stimuli even when the task distracted subjects' attention from the emotional content of the stimuli. In their studies, subjects performed an emotion focused task (judging the subjective emotional valence of slides) and a structural task (counting the number of lines inserted on each slide). These tasks are comparable with the color and object identification tasks in the present study. One common concern when interpreting the findings of studies on affective processing is that the effects might only be observed when subjects need to classify the emotional category of the stimulus. However, the results of the present study show that emotion specific effects can be observed independently of the attentional task (color or object classification) to be performed.

The ERP data provide valuable information for understand ing the behavioral results of the present study. The increased activation of emotional processing networks independently of the performed task might reflect a more efficient activation of the whole fear network of a phobic individual as soon as a possible threat (spider) is detected. According to Hebbian learning, co activation of neurons will strengthen the interconnections be tween existing network units, leading to faster and easier activation of the whole network in the future (cf. Elbert, Rocks troh, Kolassa, Schauer, \& Neuner, 2005). A fast activation of the fear network is adaptive in natural settings because it allows fast fight or flight in threat situations. Applied to the experimental setting, a fast activation of the whole fear network through the feared object triggers a fast behavioral response. This could explain why spider phobics showed facilitated responses to spi ders in the object identification task. Presumably, such an at tentional bias in the form of facilitated processing of spider pictures was not observed in the color identification task because RTs were already very fast in all subjects (a ceiling effect). In addition, a strongly responding fear network with its ready preparation for a behavioral response could counteract the emo tional Stroop interference effect, which we expected to find but indeed did not observe.

\section{Facilitation and Hypervigilance in Spider Phobics}

Consistent with Öhman, Flykt, and Esteves (2001), who found that spider and snake phobic subjects were particularly fast in detecting their feared stimulus in a matrix of neutral, fear relevant, and feared stimuli, spider phobics showed a facilitated identification of spiders. In addition, spider phobics also re sponded overall significantly faster than social phobics and showed a tendency to be faster than controls in the object iden tification task, that is, they also identified pictures of birds and flowers significantly faster than social phobics and (nonsignifi cantly) faster than controls. Presumably, the possibility that a feared object could occur on the screen induced a state of height ened alertness. This assumption would be in accordance with the hypervigilance hypothesis in trait anxious individuals proposed by Beck, Emery, and Greenberg (1985) and Eysenck (1991, 1992, 1997). According to Beck et al. (1985), anxious individuals constantly scan their environment for signs of impending threat or personal harm and selectively attend to stimuli that indicate possible danger. Eysenck $(1991,1992,1997)$ distinguishes a gen eral hypervigilance in high trait anxious individuals and a specific hypervigilance, demonstrated by the tendency to attend selec tively to threat related rather than neutral stimuli. That no fur ther facilitation due to hypervigilance was observed in the color identification is possibly due to a ceiling effect.

However, reconciling our results with Eysenck's theory is difficult because spider phobics did not differ significantly from controls in their trait anxiety values. In the light of these trait anxiety scores, Eysenck's theory would predict hypervigilance effects for social phobics, who showed significantly higher trait anxiety than spider phobics and controls, but who were signif icantly slower than spider phobics and comparable to controls in the object identification task. In conclusion, hypervigilance pro vides a coherent explanation for the tendency for faster object identification by spider phobics, but the nonelevated trait anxiety values in the spider phobic group pose a problem for Eysenck's elaboration of the theory.

The hypothesis of a general facilitation effect for fear relevant stimuli could not be confirmed: Neither social phobics nor con trols showed faster responses to spider pictures than to bird or flower pictures. In fact, apart from the spider phobics, there were no significant differences between stimulus categories in RT in the object identification task. This contrasts with evidence for faster reactions to animal targets than to plant targets, inde pendent of threat (Lipp, Derakshan, Waters, \& Logies, 2004; Tipples, Young, Quinlan, Broks, \& Ellis, 2002). However, it is difficult to compare the present results (an identification task) with those of Lipp et al. and Tipples et al. (visual search paradigms). 


\section{Possible Causes for the Absence of Stroop Interference}

An unexpected result of the present study was the absence of emotional Stroop interference in spider phobics, which also pre cluded the investigation of its neuronal correlates. One explana tion might be that the color identification task with a choice between two colors was too simple and thus led to no emotional interference. Possibly, interference might have occurred if we had used three or more colors. Second, it is possible that different formats of the emotional Stroop task are not psychomet rically equivalent. For example, Kindt, Bierman, and Brosschot (1996) reported a lack of convergent validity for card versus computer Stroop, and other studies reported that Stroop effects present in blocked designs are diminished or even absent in un blocked (randomized) designs (Ballesteros, Reales, \& Manga, 2000; Holle et al., 1997; Richards et al., 1992; Waters \& Fey erabend, 2000). Third, whether pictorial or linguistic stimuli are used seems to affect the magnitude of emotional Stroop inter ference. No study so far reported larger interference for pictorial than for linguistic stimuli a surprising result in light of the higher ecological validity of pictorial stimuli. Whereas Kindt and Brosschot (1997) found comparable interference for pictorial and linguistic stimuli in spider phobic children, Lavy and van den Hout (1993) found a smaller attentional bias for spider pictures than for spider related words in spider phobic women, and Kindt and Brosschot (1999) even found no bias at all for pictorial stimuli in spider phobic children. Possibly, linguistic stimuli in crease task difficulty, thus enhancing interference.

Finally, manual responses elicit less interference than oral ones in the classical Stroop paradigm (MacLeod, 1991; Redding $\&$ Gerjets, 1977). However, the influence of response modality on emotional Stroop interference has not been systematically investigated so far. This study was the first to use a manual response mode, and it found no evidence for an emotional Stroop interference. Future studies should investigate whether visual processing and manual reactions are more easily reconciled than verbal processing and vocal responses and whether, consequent ly, emotional Stroop interference is larger for linguistic stimuli with oral responses as compared to pictorial stimuli and manual responses.

Regardless of the lack of interference in the emotional Stroop task, the current study found that spider phobics show differ ential ERPs when viewing spider pictures an effect that was independent of the performed task. These data are consistent with the hypothesis that fear relevant stimuli lead to an extensive activation of the fear network, which triggers facilitated behavi oral responses related to the feared object.

\section{REFERENCES}

Ballesteros, S., Reales, J. M., \& Manga, D. (2000). Effects of type of design (blocked vs. randomized) on Stroop and emotional Stroop tasks. Psicothema, 12, Suppl. 2, 6063.

Beck, A. T., Emery, G., \& Greenberg, R. L. (1985). Anxiety disorders and phobias: A cognitive perspective. New York: Basic Books.

Becker, E. S., Rinck, M., Margraf, J., \& Roth, W. T. (2001). The emotional Stroop effect in anxiety disorders. General emotionality or disorder specificity. Journal of Anxiety Disorders, 15, 147159.

Cameron, C. M. (1997). Information processing approaches to phobias. In G. C. L. Davey (Ed.), Phobias. A handbook of theory, research and treatment (pp. 397 413). Chichester: Wiley.

Chatrian, G. E., Lettich, E., \& Nelson, P. L. (1998). Modified nomen clature for the $10 \%$ electrode system. Journal of Clinical Neurophys iology, 5, 183186.

Constantine, R., McNally, R. J., \& Hornig, C. D. (2001). Snake fear and the pictorial emotional Stroop paradigm. Cognitive Therapy and Research, 25, 757764

Cuthbert, B. N., Schupp, H. T., Bradley, M. M., Birbaumer, N., \& Lang, P. J. (2000). Brain potentials in affective picture processing: Covar iation with autonomic arousal and affective report. Biological Psy chology, 52, 95111

Diedrich, O., Naumann, E., Maier, S., Becker, G., \& Bartussek, D. (1997). A frontal positive slow wave in the ERP associated with emotional slides. Journal of Psychophysiology, 11, 7184.

Egeth, H. E., \& Yantis, S. (1997). Visual attention: Control, represen tation, and time course. Annual Review of Psychology, 48, 269297.

Eimer, M., Nattkemper, D., Schroger, E., \& Prinz, W. (1996). Invol untary attention. In O. Neumann \& A. F. Sanders (Eds.), Handbook of perception and action (vol. 3, pp. 155 184). San Diego, CA: Academic Press.

Elbert, T., Rockstroh, B., Kolassa, I. T., Schauer, M., \& Neuner, F. (2005). The influence of organized violence and terror on brain and mind A co constructive perspective. In P. Baltes, P. Reuter Lorenz, $\&$ F. Rosler (eds.), Lifespan development and the brain: The perspective of biocultural co constructivism. Cambridge, UK: Cambridge University Press.

Eysenck, M. W. (1991). Cognitive factors in clinical psychology: Poten tial relevance to therapy. In M. Briley \& S. E. File (Eds.), New con cepts in anxiety. London: Macmillan Press.
Eysenck, M. W. (1992). Anxiety: The cognitive perspective. Hillsdale, NJ: Lawrence Erlbaum Associates.

Eysenck, M. W. (1997). Anxiety and cognition: A unified theory. East Sussex, UK: Psychology Press.

Fredrikson, M., Annas, P., Fischer, H., \& Wik, G. (1996). Gender and age differences in the prevalence of specific fears and phobias. Behaviour Research and Therapy, 34, 3339.

Fydrich, T. (2002). Soziale Phobie und Angst Inventar. In E. Brahler, J. Schumacher, \& B. Strauß (Eds.), Diagnostische Verfahren in der Psychotherapie (pp. 335 338). Gottingen: Hogrefe.

Gratton, G., Coles, M. G. H., \& Donchin, E. (1983). A new method for off line removal of ocular artefact. Electroencephalography and Clin ical Neurophysiology, 55, 468484.

Greenhouse, S., \& Geisser, S. (1958). An extension of Box's results on the use of the F distribution in multivariate analysis. Annals of Mathe matical Statistics, 29, 885891.

Gutberlet, I., \& Miltner, W. H. R. (1999). Differentielle elektrokortikale und subkortikale Verarbeitung phobischer Reize bei Tierphobikern und gesunden Kontrollpersonen. Verhaltenstherapie, 9, 23.

Hautzinger, M., Bailer, M., Worall, H., \& Keller, F. (1995). Beck Depressions Inventar BDI, Testhandbuch (2. Auflage). Bern: Hans Huber.

Hinsch, R., \& Pfingsten, U. (2002). Gruppentraining sozialer Kompe tenzen (GSK) (4th ed). Weinheim: Beltz.

Holle, C., Neely, J. H., \& Heimberg, R. G. (1997). The effects of blocked versus random presentation and semantic relatedness of stimulus words on response to a modified Stroop task among social phobics. Cognitive Therapy and Research, 21, 681697.

Hope, D. A., Rapee, R. M., Heimberg, R. G., \& Dombeck, M. J. (1990). Representations of the self in social phobia: Vulnerability to social threat. Cognitive Therapy and Research, 21, 681696.

Ito, T. A., Larsen, J. T., Smith, N. K., \& Cacioppo, J. T. (1998). Negative information weighs more heavily on the brain: The negativity bias in evaluative categorizations. Journal of Personality and Social Psycho $\log y, 75(4), 887900$

Johnston, V. S., Miller, D. R., \& Burleson, M. H. (1986). Multiple P3s to emotional stimuli and their theoretical significance. Psychophys iology, 23, 684694.

Keil, A., Bradley, M. M., Hauk, O., Rockstroh, B., Elbert, T., \& Lang, P. J. (2002). Large scale neural correlates of affective picture process ing. Psychophysiology, 39, 641649. 
Keil, A., Muller, M. M., Gruber, T., Stolarova, M., Wienbruch, C., \& Elbert, T. (2001). Effects of emotional arousal in the cerebral hem ispheres: A study of oscillatory brain activity and event related potentials. Clinical Neurophysiology, 112, 20572068.

Kindt, M., Bierman, D., \& Brosschot, J. F. (1996). Stroop versus Stroop: Comparison of a card format and a single trial format of the standard color word Stroop task and the emotional Stroop task. Personality and Individual Differences, 21, 415422.

Kindt, M., Bierman, D., \& Brosschot, J. F. (1997). Cognitive bias in spider fear and control children: Assessment of emotional interference by card format and a single trial format of the Stroop task. Journal of Experimental Child Psychology, 66, 163179.

Kindt, M., \& Brosschot, J. F. (1997). Phobia related cognitive bias for pictorial and linguistic stimuli. Journal of Abnormal Psychology, 106, 644648.

Kindt, M., \& Brosschot, J. F. (1999). Cognitive bias in spider phobic children: Comparison of a pictorial and a linguistic spider Stroop. Journal of Psychopathology and Behavioral Assessment, 21, 207220.

Kindt, M., \& van den Hout, M. (2001). Selective attention and anxiety: A perspective on developmental issues and the causal status. Journal of Psychopathology and Behavioral Assessment, 23, 193202.

Kindt, M., van den Hout, M., de Jong, P., \& Hoekzema, B. (2000). Cognitive bias for pictorial and linguistic threat cues in children. Journal of Psychopathology and Behavioral Assessment, 22, 201219.

Klorman, R., Weerts, T. C., Hastings, J. E., Melamed, B. G., \& Lang, P. J. (1974). Psychometric description of some specific fear question naires. Behavior Therapy, 5, 401409 .

Lang, P. J. (1980). Behavioral treatment and bio behavioral assessment: Computer applications. In J. B. Sidowski, J. H. Johnson, \& T. A. Williams (Eds.), Technology in mental health care delivery systems (pp. 119 137). Norwood, NJ: Ablex Publishing.

Lang, P. J., Bradley, M. M., \& Cuthbert, B. N. (1997). Motivated at tention: Affect, activation, and action. In P. J. Lang, R. F. Simons, \& M. Balaban (Eds.), Attention and orienting: Sensory and motivational processes (pp. 97 135). Hillsdale, NJ: Lawrence Erlbaum Associates.

Lang, P. J., Bradley, M. M., Fitzsimmons, J. R., Cuthbert, B. N., Scott, J. D., Moulder, B., et al. (1998). Emotional arousal and activation of the visual cortex: An fMRI analysis. Psychophysiology, 35, 199210.

Laurian, S., Bader, M., Lanares, J., \& Oros, L. (1991). Topography of event related potentials elicited by visual stimuli. International Journal of Psychophysiology, 10, 231238.

Laux, L., Glanzmann, P., Schaffner, P., \& Spielberger, C. D. (1981). Das State Trait Angstinventar (STAI G) [Spielberger, C. D., Gorsuch, R. L., \& Lushene, R. E. 1970. The State Trait Anxiety Inventory. Palo Alto, CA: Consulting Psychologists Press]. Weinheim: Beltz.

Lavy, E., \& van den Hout, M. (1993). Selective attention evidenced by pictorial and linguistic Stroop tasks. Behavior Therapy, 24, 645657.

Lavy, E. H., van den Hout, M., \& Arntz, A. (1993). Attentional bias and spider phobia: Conceptual and clinical issues. Behaviour Research and Therapy, 31, 1724.

Lipp, O. V., Derakshan, N., Waters, A. M., \& Logies, S. (2004). Snakes and cats in the flowerbed: Fast detection is not specific to pictures of fear relevant animals. Emotion, 4, 233250.

MacLeod, C. M. (1991). Half a century of research on the Stroop effect: An integrative review. Psychological Bulletin, 109, 163203.

Martin, M., Horder, P., \& Gregory, V. (1992). Integral bias in naming of phobia related words. Cognition and Emotion, 6, 479486.

Martin, M., \& Jones, G. V. (1995). Integral bias in the cognitive process ing of emotionally linked pictures. British Journal of Psychology, 86, 419435 .

Mathews, A., \& MacLeod, C. (1985). Selective processing of threat cues in anxiety states. Behaviour Research and Therapy, 31, 563569.

Mathews, A., \& MacLeod, C. (1987). An information processing ap proach to anxiety. Journal of Cognitive Psychotherapy: An Interna tional Quarterly, 1, 105115

McNally, R. J., Amir, N., \& Lipke, H. J. (1996). Subliminal processing of threat cues in posttraumatic stress disorder. Journal of Anxiety Disorders, 10, 115128.

Merikangas, K., Angst, J., Eaton, W., Canino, G., Rubio Stipec, M., Wacker, H., et al. (1996). Comorbidity and boundaries of affective disorders with anxiety disorders and substance abuse: Results of an international task force. British Journal of Psychiatry, 168, Suppl. 30, 4958.

Mineka, S., \& Ohman, A. (2002). Phobias and preparedness: The selec tive, automatic, and encapsulated nature of fear. Biological Psychi atry, 52, 927937.

Mini, A., Palomba, D., Angrilli, A., \& Bravi, S. (1996). Emotional in formation processing and visual evoked brain potentials. Perceptual and Motor Skills, 83, 143152.

Naumann, E., Becker, G., Maier, S., Diedrich, O., \& Bartussek, D. (1997). Ereigniskorrelierte Potentiale auf emotionale Bilder: Einfluß der Darbietungszeit. Zeitschrift für Experimentelle Psychologie, $X L I V, 163185$.

Ohman, A. (1979). The orienting response, attention and learning: An information processing perspective. In H. D. Kimmel, E. H. van Olst, \& J. F. Orlebeke (Eds.), The orienting reflex in humans (pp. 443 471). Hillsdale, NJ: Lawrence Erlbaum Associates.

Ohman, A. (1993). Fear and anxiety as emotional phenomena: Clinical phenomenology, evolutionary perspectives and information process ing mechanisms. In M. Lewis \& J. M. Haviland (Eds.), Handbook of emotions (pp. 511 536). New York: Guilford Press.

Ohman, A., Esteves, F., Flykt, A., \& Soares, J. J. F. (1993). Gateways to consciousness: Emotion, attention, and electrodermal activity. In J. C. Roy, W. Boucsein, D. C. Fowles, \& J. H. Gruzelier (Eds.), Progress in electrodermal research (pp. 137 157). New York: Plenum.

Ohman, A., Flykt, A., \& Esteves, F. (2001). Emotion drives attention: Detecting the snake in the grass. Journal of Experimental Psychology: General, 130, 466478

Ohman, A., \& Mineka, S. (2001). Fears, phobias, and preparedness: Toward an evolved module of fear learning. Psychological Review, $108,483522$.

Oldfield, R. C. (1971). The assessment and analysis of handedness: The Edinburgh Inventory. Neuropsychologia, 9, 97113.

Ost, L. G. (1989). One session treatment for specific phobias. Behaviour Research and Therapy, 27, 17.

Palomba, D., Angrilli, A., \& Mini, A. (1997). Visual evoked potentials, heart rate responses and memory to emotional pictorial stimuli. International Journal of Psychophysiology, 27, 5567.

Radilovà, J. (1982). The late positive components of visual evoked re sponses sensitive to emotional factors. Activitas Nervosa Superior, Suppl. 3, 334.

Radilovà, J., Figar, S., \& Radil, T. (1983). Sexual arousal and visual perception. Activitas Nervosa Superior, 25, 168170.

Radilovà, J., Figar, S., \& Radil, T. (1984). Emotional states influence the visual evoked potentials. Activitas Nervosa Superior, 26, 159160.

Redding, G. M., \& Gerjets, D. A. (1977). Stroop effect: Interference and facilitation with verbal and manual responses. Perceptual and Motor Skills, 1, 1117.

Richards, A., French, C. C., Johnson, W., Naparstek, J., \& Williams, J. (1992). Effects of emotion manipulation and anxiety on performance of an emotional Stroop task. British Journal of Clinical Psychology, $83,479491$.

Schneier, F. R., Johnson, J., Hornig, C. D., Liebowitz, M. R., \& Weissman, M. M. (1992). Social phobia: Comorbidity and morbidity in an epidemiological sample. Archives of General Psychiatry, 45, 282288.

Schupp, H. T., Cuthbert, B. N., Bradley, M. M., Cacioppo, J. T., Ito, T., \& Lang, P. J. (2000). Affective picture processing: The late positive potential is modulated by motivational relevance. Psychophysiology, $37,257261$.

Schupp, H. T., Junghofer, M., Weike, A. I., \& Hamm, A. O. (2003). Emotional facilitation of sensory processing in the visual cortex. Psy chophysiological Science, 14, 713.

Seligman, M. E. P. (1971). Phobias and preparedness. Behavior Therapy, 2,307320 .

Stein, M. B., Fuetsch, M., Muller, N., Hofler, M., Lieb, R., \& Wittchen, H. U. (2001). Social anxiety disorder and the risk of depression: A prospective community study of adolescents and young adults. Archives of General Psychiatry, 58, 251256.

Stroop, J. R. (1935). Studies of interference in serial verbal reactions. Journal of Experimental Psychology, 18, 643662.

Tipples, J., Young, A. W., Quinlan, P., Broks, P., \& Ellis, A. W. (2002). Searching for threat. The Quarterly Journal of Experimental Psycho $\log y, 55 A, 10071026$. 
Turner, S. M., Beidel, D. C., Dancu, C. V., \& Stanley, M. A. (1989). An empirically derived inventory to measure social fears and anxiety: The Social Phobia and Anxiety Inventory. Psychological Assessment, 1, 3540.

Waters, A. J., \& Feyerabend, C. (2000). Determinants and effects of attentional bias in smokers. Psychology of Addictive Behaviors, 14, 111120.

Watts, F. N., McKenna, F. P., Sharrock, R., \& Trezise, L. (1986). Colour naming of phobia related words. British Journal of Psychology, 77, 97108.
Williams, J., Mark, G., Watts, F. N., MacLeod, C., \& Mathews, A. (1997). Cognitive psychology and emotional disorders. Chichester: Wiley.

Wittchen, H. U., Wunderlich, U., Gruschwitz, S., \& Zaudig, M. (1997). Strukturiertes Klinisches Interview für DSM IV [Structured clinical interview for DSM IV]. Gottingen: Hogrefe. 